\section{Effects of Substrate Water Content on Morphology and Physiology of Rosemary, Canadian Columbine, and Cheddar Pink}

\author{
Shuyang Zhen and Stephanie E. Burnett ${ }^{1}$ \\ School of Food and Agriculture, University of Maine, 5722 Deering Hall, \\ Orono, ME 04469
}

Michael E. Day

School of Forest Resources, University of Maine, 5755 Nutting Hall, Orono, ME 04469

\author{
Marc W. van Iersel \\ Department of Horticulture, The University of Georgia, 1111 Miller Plant \\ Sciences Building, Athens, GA 30602
}

Additional index words. herbaceous perennial, moisture sensors, photosynthesis, volumetric water content

\begin{abstract}
Two experiments were conducted to determine how different substrate volumetric water contents ( $\theta$ equals volume of water per volume of substrate) affected morphology and physiology of three popular perennials using a capacitance sensorautomated irrigation system. In the first study, rosemary (Rosmarinus officinalis) was grown at one of eight $\theta$ set points ranging from 0.05 to $0.40 \mathrm{~L} \cdot \mathrm{L}^{-1}$. In the second study, Canadian columbine (Aquilegia canadensis 'Pink Lanterns') and cheddar pink (Dianthus gratianopolitanus 'Bath's Pink') were grown at one of nine $\theta$ set points ranging from 0.05 to $0.45 \mathrm{~L} \cdot \mathrm{L}^{-1}$. Total leaf number and area as well as shoot fresh and dry weight of rosemary plants grown at $\theta$ of $0.20 \mathrm{~L} \cdot \mathrm{L}^{-1}$ or greater were approximately twice that of those grown at lower $\theta$. Canadian columbine height increased as $\theta$ increased. Leaf area of cheddar pink grown at $\theta$ of $0.35 \mathrm{~L} \cdot \mathrm{L}^{-1}$ or higher was twice that of plants grown at the lowest $\theta$. Shoot dry weight of Canadian columbine was not significantly affected by $\theta$. Shoot dry weight of cheddar pink responded quadratically to increasing $\theta$ and peaked at $\theta$ of $0.35 \mathrm{~L} \cdot \mathrm{L}^{-1}$. $\theta$ also significantly influenced photosynthetic activities; net photosynthetic rate $\left(\mathrm{A}_{\mathrm{N}}\right)$ and stomatal conductance $\left(g_{\mathrm{s}}\right)$ of Canadian columbine increased with increasing $\theta$. $A_{N}$ of cheddar pink also increased as $\theta$ increased. Greater water volumes were applied to maintain higher $\theta$ set points. Irrigation water use efficiency (IWUE = shoot dry weight $\div$ total amount of water applied per plant) of Canadian columbine and cheddar pink was not influenced by $\theta$. Growth of all three plants was reduced when grown at lower $\theta$; in the case of cheddar pink and Canadian columbine, this was attributable at least in part to reduced $A_{N}$.
\end{abstract}

Greenhouse operations often use high volumes of water for irrigation. In recent years, growers have faced increasing pressure to reduce water input as a result of global water shortages and increasing irrigation costs (Beeson et al., 2004). One way to conserve

\footnotetext{
Received for publication 25 Sept. 2013. Accepted for publication $14 \mathrm{Feb} .2014$.

Maine Agriculture and Forestry Experiment Station Publication \#3353.

We thank the American Floral Endowment for providing funding to support this research. This work is based on research funded in part by Hatch Multistate Grant \#ME0-31401 from the USDA National Institute of Food and Agriculture. We thank Lois Stack, Jonathan Foster, and Marianne Sarrantonio for providing helpful feedback on an early draft of this manuscript. Thank you to Julie Hintz and Bradly Libby for technical support.

${ }^{1}$ To whom reprint requests should be addressed; e-mail sburnett@maine.edu.
}

2012). Providing plants with the exact amount of water needed can optimize plant growth, improve irrigation efficiency, and increase profitability (Belayneh et al., 2013; Chappell et al., 2013; Lichtenberg et al., 2013). However, irrigation decisions are often affected by factors other than plant water needs such as labor costs, the irrigation system being used, and the way irrigation is automated. In addition, water requirements for most herbaceous perennials remain unclear. As a result of lack of guidelines on how much water should be applied, growers often apply excessive water to reduce the risk of drought-induced crop shrinkage. Overwatering not only increases water waste and nutrient leaching, but also increases plants' susceptibility to root rot diseases such as Phytophthora and Pythium (Nelson, 2012).

Additionally, precise knowledge of plant water requirements permits growers to control stem elongation and regulate plant form by deliberately growing plants at suboptimal irrigation regimes. Moderate water stress reduces plant growth and elongation in many species and may be used as a substitute for chemical growth retardants in commercial greenhouses. For instance, Burnett and van Iersel (2008) used a capacitance sensorautomated irrigation system to maintain substrates constantly at a range of $\theta$ levels and found that gaura (Gaura lindheimeri) had shorter branches and was more compact when grown at lower $\theta$, yet some species showed no significant morphological changes when grown under drought conditions such as agastache (Agastache urticifolia), cardinal flower (Lobelia cardinalis), and lantana (Lantana camara) (Niu et al., 2006; Starman and Lombardini, 2006). Other species such as purple coneflower (Echinacea purpurea) and Shasta daisy (Leucanthemum $\times$ superbum) had substantially reduced visual quality (i.e., noticeable leaf burn and stem dieback) when exposed to moderate drought (watering at 2-week intervals) (Zollinger et al., 2006). The practice of using water stress to control plant growth might be effective, but it could potentially impair plant quality without a thorough understanding of crop-specific water requirements.

Plants vary in sensitivity to water stress and often differ in their responses to severity and duration of water stress (Kramer and Boyer, 1995). Determining both the morphological and physiological responses of plants grown under various $\theta$ levels is key to making proper irrigation decisions, and improved irrigation strategies could reduce water consumption, optimize plant growth, and regulate plant form. To accomplish these goals, accurate control and monitoring of substrate water status is necessary (Jones, 2007). An automated irrigation system using capacitance sensors, developed by Nemali and van Iersel (2006), allows for accurate $\theta$ control. Irrigation is automatically activated according to the amount of water lost through evapotranspiration so that substrates are maintained at constant $\theta$ set points. Plant morphological and physiological responses to continuous 
steady-state water stress can be accurately evaluated using this system (Nemali and van Iersel, 2006). This innovative system also shows great potential to reduce or eliminate leaching, thus reducing runoff of fertilizers or pesticides (Burnett and van Iersel, 2008; Garland et al., 2012; Nemali and van Iersel, 2006; van Iersel et al., 2010).

This study explores the effects of water stress on plant morphology and physiology, including the ability of plants to use water to produce biomass. We selected three important horticultural species for which water requirements have not been quantified. Rosemary (Rosmarinus officinalis) is an evergreen shrub/subshrub native to the Mediterranean region that is widely used in greenhouse and nursery container plant production [U.S. Department of Agriculture (USDA), 2013]. Canadian columbine (Aquilegia canadensis 'Pink Lanterns') and cheddar pink (Dianthus gratianopolitanus 'Bath's Pink') are popular herbaceous perennials that are hardy to USDA hardiness zones 3 to 8 ; they thrive in a wide range of areas in the United States (Armitage, 2008; USDA, 2013). Excellent soil drainage is recommended for both Canadian columbine and cheddar pink (Armitage, 2008). Our objectives were: 1) to determine the optimal $\theta$ for growing high-quality and high-yield rosemary in greenhouses; and 2) to determine how $\theta$ affects morphology and physiology of Canadian columbine and cheddar pink and quantify the amount of water needed for optimal growth of these two species.

\section{Materials and Methods}

Two experiments were conducted in a glass greenhouse from Aug. 22 to 31 Oct. 2011 (rosemary) and from 7 Apr. to 18 June 2012 (Canadian columbine and cheddar pink).

\section{Expt. 1}

Pre-vernalized rosemary plugs from a commercial grower were transplanted into $1.76-\mathrm{L}$ plastic containers $(15.2 \mathrm{~cm}$ in diameter) filled with a soilless substrate [Fafard $1 \mathrm{p}$, $80 \%$ peat: $20 \%$ perlite (v/v); Fafard, Agawam, $\mathrm{MA}]$. Slow-release fertilizer $(18 \mathrm{~N}-2.6 \mathrm{P}-10 \mathrm{~K}$; Osmocote 18-6-12; Everris, Dublin, $\mathrm{OH}$ ) was incorporated into the substrate at a rate of $4.9 \mathrm{~g} \cdot \mathrm{L}^{-1}$ before transplanting. Plants were hand-watered for 3 weeks to promote plant establishment. After 3 weeks, a capacitance sensor-automated irrigation system similar to the one Nemali and van Iersel (2006) developed was used to control irrigation.

Rosemary was grown at one of eight $\theta$ set points: $0.05,0.10,0.15,0.20,0.25,0.30,0.35$, or $0.40 \mathrm{~L} \cdot \mathrm{L}^{-1}$. Based on a substrate moisture release curve, $\theta$ of $0.26 \mathrm{~L} \cdot \mathrm{L}^{-1}$ and $0.44 \mathrm{~L} \cdot \mathrm{L}^{-1}$ are equivalent to matric potentials of $-45 \mathrm{kPa}$ and $-5 \mathrm{kPa}$, respectively, in the growing substrate used for these experiments (van Iersel et al., 2013). One soil moisture sensor (EC-5; Decagon Devices, Pullman, WA) was inserted vertically at an $\approx 45^{\circ}$ angle into the substrate of one plant in each experimental unit. Sensor voltage output was measured every $3 \mathrm{~min}$. Sensors were connected to a multiplexer (AM 16/32B; Campbell Scientific, Logan, UT) connected to a data logger (CR10X; Campbell Scientific). The data logger was programmed to convert voltage to $\theta$ using a substrate-specific calibration equation calculated on-site $(\theta=$ voltage $\times 1.8862-$ $0.5624)$. When $\theta$ fell below the set point for a treatment, a normally closed solenoid valve connected to a relay driver $(2.54 \mathrm{~cm}, 24-\mathrm{VAC}$ solenoid valves) was programmed to open for $1 \mathrm{~s}$. Plants were then irrigated using dribble stakes (Model 1101001-B; Netafim, Fresno, CA) connected to a pressure-compensated emitter (Netafim).

Plant height (from the substrate surface to the tallest point on the plant) and width at the widest point were measured weekly after all substrates reached their $\theta$ set points. Only the four plants in the middle of each experimental unit were measured to avoid edge effects. Plants were harvested 10 weeks after initiation of the experiment, when they were considered marketable-sized. The number of leaves per plant was counted and total leaf area (LI-3000A Portable Area Meter; LICOR Biosciences, Lincoln, NE) was measured on the plants grown in the containers with moisture sensors in each experimental unit. Shoots were cut off at the substrate surface and fresh weight was immediately recorded; shoot dry weight was determined after drying in a soil drying room for 2 weeks.

Treatments were arranged in a completely randomized design for rosemary. Each experimental unit consisted of eight plants (subsamples) in four rows of two containers each. Data were collected from the four plants in the middle to avoid edge effects. There was one replication of each treatment. Data collected from the four subsamples in each experimental unit were averaged before statistical analysis. Data were then analyzed using linear and quadratic regression models in Statistical Analysis Systems (Version 9.2; SAS Institute, Cary, NC). The model that was the best fit was selected based on $P$ values and $R^{2}$.

\section{Expt. 2}

Pre-vernalized Canadian columbine and cheddar pink cuttings were obtained from a commercial grower for the second experiment (72-cell plugs; Green Leaf Plants ${ }^{\circledR}$, Lancaster, PA). Rooted cuttings were transplanted using the same substrates, fertilizers, and containers described for Expt. 1.

A similar irrigation system was used to control irrigation in Expt. 2. However, for Canadian columbine and cheddar pink, soil moisture sensors that measure both $\theta$ and substrate temperature (5TM; Decagon Devices, Pullman, WA) were used rather than sensors that just measure $\theta$. The data logger program converted sensor output (dielectric permittivity) to $\theta$ using a substrate-specific calibration equation that was calculated on-site: $\theta=(50 \times$ dielectric permittivity -66.35897$) \times$ $0.000905, r^{2}=0.98$. For the calibration equation, $\theta$ was maintained constantly at one of nine set points: $0.05,0.10,0.15,0.20,0.25,0.30$, $0.35,0.40$, or $0.45 \mathrm{~L} \cdot \mathrm{L}^{-1}$. The amount of water applied to each treatment during an irrigation event was measured before the experiment. The data logger counted the number of irrigation events for each experimental unit throughout the course of the experiment. Then, the total irrigation volume applied to each plant was calculated by multiplying the number of irrigation events by the volume of a single irrigation event divided the number of plants in an experimental unit (eight).

As described in the previous experiment, plant height and widest width were measured weekly after all substrates reached their $\theta$ set points. After 10 weeks, plants were harvested, and the number of leaves, leaf area, shoot fresh weight, and shoot dry weight was noted as in Expt. 1. IWUE was calculated using the following equation: IWUE $=$ shoot dry weight $(\mathrm{g} /$ plant $) \div$ total irrigation (g/plant). As a result of rain events on Day 20 and Day 35, two treatments $(\theta=$ 0.25 and $\theta=0.40$ for the columbine) received additional water that dripped through the greenhouse glazing. For these two treatments, the additional water volume was calculated as follows: ( $\theta$ after the rain event $-\theta$ before the rain event) $* 1.76$, where $1.76(\mathrm{~L})$ is the volume of substrate in each container. This value was used to adjust the total irrigation volume and IWUE for those two treatments.

Leaf gas exchange and chlorophyll fluorescence of cheddar pink and Canadian columbine were measured on 13 and 14 June. These measurements were taken on uppermost fully expanded leaves using a portable open-flow photosynthetic system (Li-6400-40, LI-COR, Lincoln, NE) equipped with a leaf chamber fluorometer. The temperature inside the leaf chamber was set at $25{ }^{\circ} \mathrm{C}$ and photosynthetically active radiation was maintained at $1000 \mu \mathrm{mol} \cdot \mathrm{m}^{-2} \cdot \mathrm{s}^{-1}$. Measurements were taken on one or two intact leaves that had acclimated to light levels inside the chamber for at least $3 \mathrm{~min}$. Data represent the average of 10 or 20 measurements taken from these acclimated leaves. Photosynthesis was measured only on plants grown in containers in which sensors were installed. Chlorophyll fluorescence was measured on uppermost fully expanded leaves that were dark-adapted overnight using dark-adapting clips (Li-6400-40; LICOR). The ratio of variable to maximum fluorescence $\left(\mathrm{F}_{\mathrm{v}} / \mathrm{F}_{\mathrm{m}}\right)$ was measured $(\mathrm{Li}-$ 6400-40; LI-COR); this is an estimate of the maximum efficiency of photosystem II (PSII) for electron transport. Reduced $\mathrm{F}_{\mathrm{v}} / \mathrm{F}_{\mathrm{m}}$ indicates damage to PSII, which could be the result of drought stress (Maxwell and Johnson, 2000).

The second experiment (Canadian columbine and cheddar pink) was a two-by-nine factorial design (species $\times \theta$ ); treatments were arranged in a completely randomized design. Otherwise, the experimental design and analysis was the same as described for the first experiment. For cheddar pink, plants grown at a $\theta$ of 0.30 were considered outliers. Data for that treatment were not included in the analysis and are not shown. 


\section{Results and Discussion}

Expt. 1

Plant morphology. There was a trend for rosemary plants to be larger when they were grown at higher $\theta$. However, it is important to note that rosemary had more than $50 \%$ mortality when grown at $\theta$ set point of $0.05 \mathrm{~L} \cdot \mathrm{L}^{-1}$ (data not shown). Therefore, this $\theta$ should be avoided. Plants grown in drier substrates were smaller, though. Width of rosemary increased with increasing $\theta$, giving rosemary plants grown at a lower $\theta$ a narrower, more upright habit (Fig. 1C). Only data collected when plants were harvested are presented. However, there was a trend for width to increase as $\theta$ increased throughout the experiment (data not shown). Rosemary generally had longer, more flexible branches when grown at $\theta$ higher than $0.20 \mathrm{~L} \cdot \mathrm{L}^{-1}$, making them much wider and less compact. Other ornamental plants such as gaura and miniature rose (Rosa $\times$ hybrida) are more compact when grown under continuous steady-state moisture



Fig. 1. Effects of substrate volumetric water content $(\theta)$ on height of Canadian columbine $(\mathbf{A})$ and cheddar pink $(\mathbf{B})$ and width of rosemary $(\mathbf{C})$ and cheddar pink (D). Data were collected in the final week of the experiment. Data represent the mean of four subsamples. $P \leq 0.05$ was considered statistically significant.

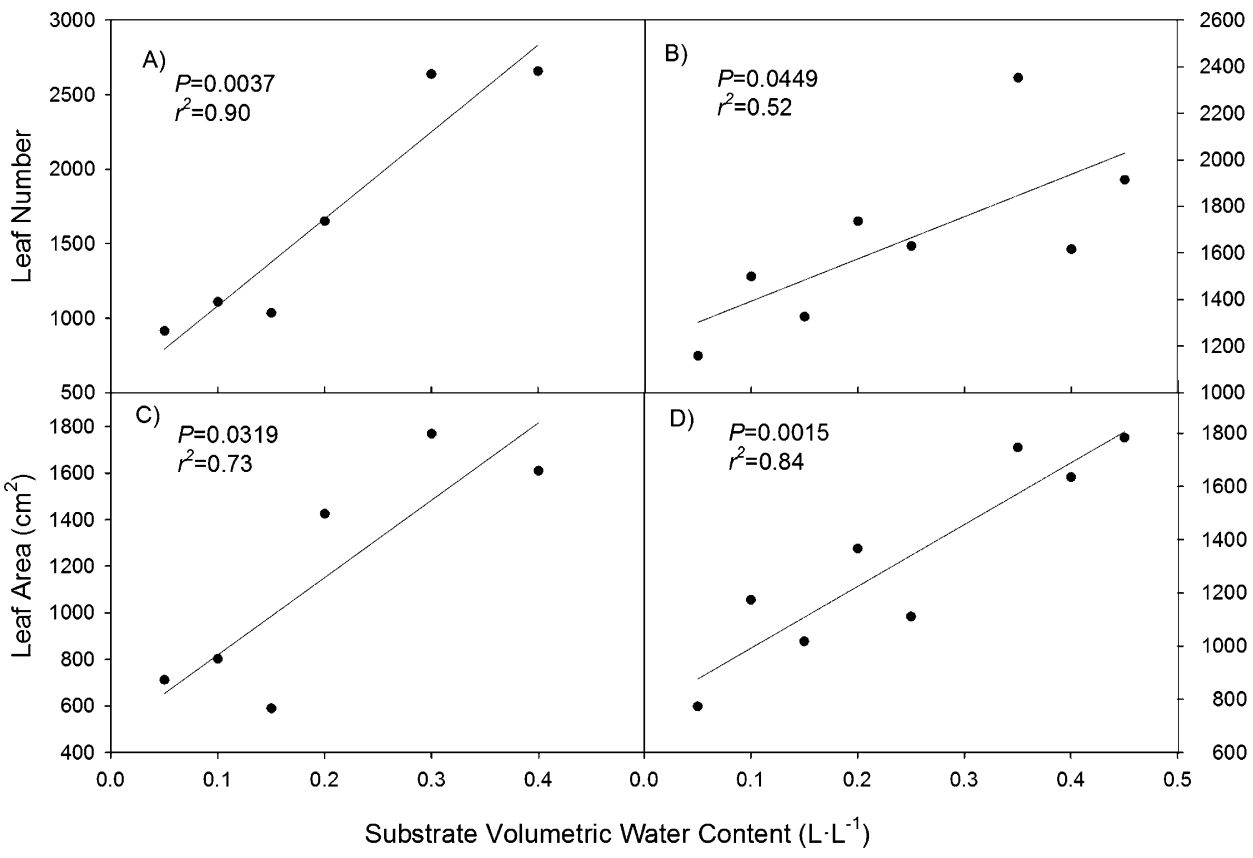

Fig. 2. Effects of substrate volumetric water content $(\theta)$ on total leaf number of rosemary $(\mathbf{A})$ and cheddar pink $(\mathbf{B})$ and total leaf area of rosemary $(\mathbf{C})$ and cheddar pink (D) at harvest. Data represent the mean of four subsamples. $P \leq 0.05$ was considered statistically significant. 
stress (Burnett and van Iersel, 2008; Williams et al., 1999).

Total leaf number and area of rosemary (Figs. 2A and 2C) increased with increasing $\theta$. Leaf number and area of rosemary grown at $\theta 0.30 \mathrm{~L} \cdot \mathrm{L}^{-1}$ or greater were more than twice that of plants grown at $\theta 0.15 \mathrm{~L} \cdot \mathrm{L}^{-1}$ or less. Reduced leaf expansion is an easily observed symptom of water stress, because turgor pressure is the driving force for cell elongation (Taiz and Zeiger, 2010). Turgor pressure, in turn, typically decreases with decreasing substrate water availability (Boyer, 1970; Taiz and Zeiger, 2010). Total leaf area of coral bells was reported to increase linearly with increasing $\theta$ (Garland et al., 2012) and drought stress reduced leaf area of scarlet sage (Salvia splendens), mealycup sage (Salvia farinacea), yarrow (Achillea 'Moonshine'), lantana (Lantana camara), and abutilon
(Abutilon $\times$ hybridum) (Eakes et al., 1991; Kim and van Iersel, 2009; Starman and Lombardini, 2006).

Shoot fresh and dry weight of rosemary increased as plants were grown with more water in the substrate. Rosemary plants with the greatest mass were grown in substrates maintained at the highest $\theta$ set point (Figs. 3A and 3C). Many other ornamental crops, including gaura, petunia (Petunia
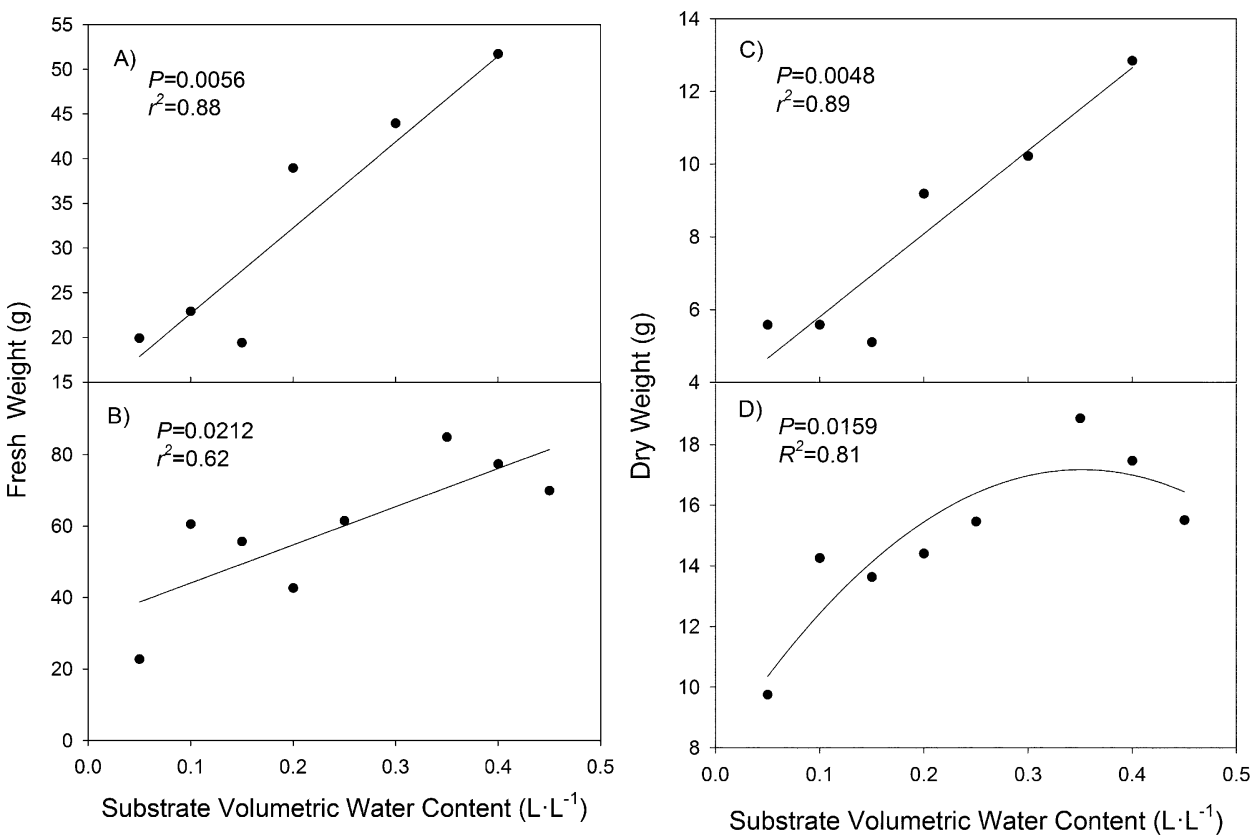

Fig. 3. Shoot fresh and dry weight of rosemary (A and $\mathbf{C}$ ) and cheddar pink ( $\mathbf{B}$ and $\mathbf{D})$ as a function of substrate volumetric water content. Data represent the mean of four subsamples. $P \leq 0.05$ was considered statistically significant.
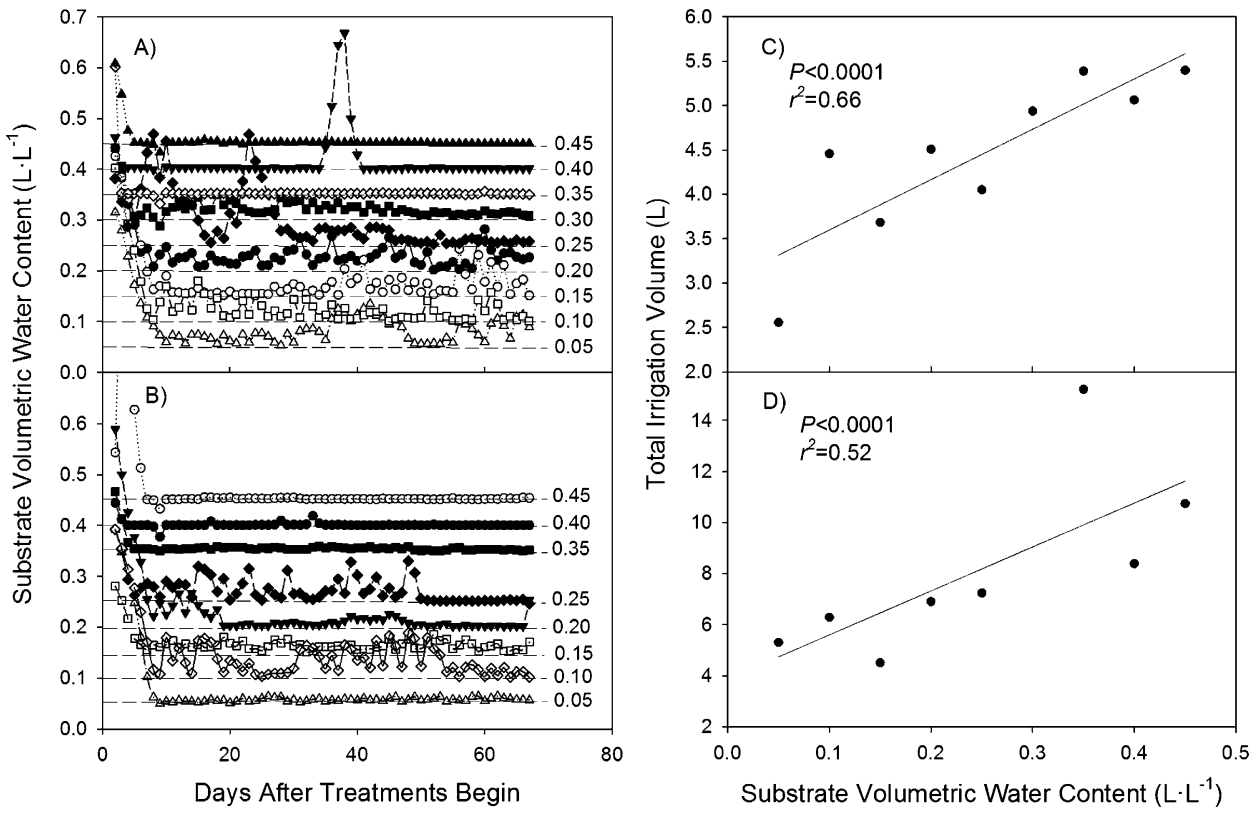

Fig. 4. Daily average substrate volumetric water content $(\theta)$ and the total amount of water applied per plant over the duration of the experiment for Canadian columbine (A and $\mathbf{C}$ ) and cheddar pink (B and $\mathbf{D})$, respectively. Dashed horizontal lines indicate $\theta$ set points. Data points for $\theta$ of $0.30 \mathrm{~L} \cdot \mathrm{L}^{-1}$ are not shown here or in the following figures for cheddar pink, because that treatment was considered an outlier. $P \leq 0.05$ was considered statistically significant. 
$\times$ hybrida), coral bells, dusty miller (Cineraria maritima), plumbago (Plumbago auriculata), fan flower (Scaevola aemula), and zonal geranium (Pelargonium $\times$ hortorum), have shown similar reductions in shoot biomass accumulation with decreasing $\theta$ (Burnett and van Iersel 2008; Garland et al., 2012; Niu et al., 2006; Sánchez-Blanco et al., 2009; Starman and Lombardini, 2006; van Iersel et al., 2010). We recommend that rosemary growers maintain substrates at $\theta$ greater than $0.20 \mathrm{~L} \cdot \mathrm{L}^{-1}$ to obtain the largest overall plants for landscapes or to obtain the greatest yield.

\section{Expt. 2}

Substrate water content and total irrigation applied. All substrates reached their $\theta$ set points in 4 to $9 \mathrm{~d}$ (Fig. 4A-B). The capacitance sensorautomated irrigation system was able to maintain $\theta$ close to the set points throughout the remainder of the experiment (Fig. 4A-B). Greater fluctuations in $\theta$ observed at set points of $0.25 \mathrm{~L} \cdot \mathrm{L}^{-1}$ or lower were probably caused by decreased hydraulic conductivity of substrates at lower $\theta$ (Naasz et al., 2005). Similar fluctuations were previously reported (Burnett and van Iersel, 2008; Garland et al., 2012; Nemali and van Iersel, 2006; van Iersel et al., 2010). Total irrigation volume increased linearly with increasing $\theta$, ranging from 2.6 to $5.4 \mathrm{~L} /$ plant (Canadian columbine) and from 4.6 to $15.3 \mathrm{~L} /$ plant (cheddar pink) over a period of $70 \mathrm{~d}$ (Fig. 4C-D). Previous researchers observed a similar correlation between irrigation applied and $\theta$ (Burnett and van Iersel, 2008; Garland et al., 2012). IWUE of Canadian columbine and cheddar pink was not significantly influenced by $\theta$ (data not shown).

Plant morphology. Cheddar pink grown at all $\theta$ survived, although leaves of plants grown at a $\theta$ of $0.05 \mathrm{~L} \cdot \mathrm{L}^{-1}$ were wilting, yellow, and beginning to senesce, which affected their aesthetic value. Like with rosemary, survival of Canadian columbine at the lowest $\theta\left(0.05 \mathrm{~L} \cdot \mathrm{L}^{-1}\right)$ was reduced $(50 \%$; data not shown). For both of these species, plants were considered marketable at $\theta$ of $0.10 \mathrm{~L} \cdot \mathrm{L}^{-1}$ or higher (Cheddar pink) or $\theta$ of $0.15 \mathrm{~L} \cdot \mathrm{L}^{-1}$ or higher (Canadian Columbine). Height of both species and width of Cheddar pink increased with increasing $\theta$ (Figs. $1 \mathrm{~A}-\mathrm{B}$ and 1D). Average height of Canadian columbine increased from 30 to $45 \mathrm{~cm}$ when grown at $\theta$ of $0.05 \mathrm{~L} \cdot \mathrm{L}^{-1}$ and $0.40 \mathrm{~L} \cdot \mathrm{L}^{-1}$, respectively (Fig. 1A). Like with Expt. 1, only the last week of data is shown, but the trend presented in Figure 2 was observed through the duration of Expt. 2 (data not shown).

The reduction in height of Canadian columbine indicates that there is a potential for using irrigation to control height of Canadian columbine. Previous research indicates that chemical growth retardants do not reduce columbine height or width (Latimer and Oetting, 1999). Latimer and Oetting (1999) reported that moisture stress-conditioned plants were larger than controls (Latimer and Oetting, 1999). However, our research indicates that maintaining constant, low $\theta$ with moisture sensors reduced Canadian columbine shoot elongation. Growers who wish to reduce columbine size should consider using sensor-automated irrigation because plant growth retardants are not an option.

Like observed with rosemary, both the leaf number and area of cheddar pink were greater when plants were grown at higher $\theta$ (Figs. 2B and 2D). Individual leaves of cheddar pink were visibly larger when grown at higher $\theta$; total leaf area of plants grown at $\theta$ of $0.35 \mathrm{~L} \cdot \mathrm{L}^{-1}$ or higher was twice that of plants grown at $\theta$ of $0.05 \mathrm{~L} \cdot \mathrm{L}^{-1}$. Shoot dry weight of cheddar pink responded quadratically to increasing $\theta$ and peaked at $\theta$ of $0.35 \mathrm{~L} \cdot \mathrm{L}^{-1}$ (Fig. 3D). The responses of cheddar pink biomass production to $\theta$ were at least partially caused by an overall reduction in plant photosynthetic surface area at low $\theta$ (Fig. 3C-D). Leaf number and area and shoot fresh and dry weight of Canadian columbine were not significantly affected by $\theta$. It is important to note that the slow-release fertilizer used in this experiment would have released more nutrients at higher $\theta$. However, it is unlikely that nutrition was involved in observed reductions in plant size because nutrient deficiencies were not observed in any plants.

Photosynthesis and chlorophyll fluorescence. Gas exchange and chlorophyll fluorescence data suggest a further, physiological basis for the observed relationships between $\theta$ and plant growth. $\mathrm{A}_{\mathrm{N}}$ of Canadian columbine and cheddar pink increased with increasing $\theta$ (Fig. 5A-B). Decreasing $\theta$ from 0.45 to $0.05 \mathrm{~L} \cdot \mathrm{L}^{-1}$ caused $\mathrm{A}_{\mathrm{N}}$ to decrease from 28 to $4.83 \mu \mathrm{mol} \cdot \mathrm{m}^{-2} \cdot \mathrm{s}^{-1}$ (cheddar pink) and from 11.5 to $8.1 \mu \mathrm{mol} \cdot \mathrm{m}^{-2} \cdot \mathrm{s}^{-1}$ (Canadian columbine) (Fig. $5 \mathrm{~A}-\mathrm{B}) . g_{\mathrm{s}}$ of Canadian columbine decreased linearly with decreasing $\theta$ (Fig. 5C). There was a trend for $g_{\mathrm{s}}$ of cheddar pink to decrease with decreasing $\theta$ as well; however, this trend was not significant (data not shown). When $g_{\mathrm{s}}$ is lower, $\mathrm{CO}_{2}$ supply for carboxylation in the Calvin cycle can become limiting, which in turn reduces photosynthesis. A reduction in $g_{\mathrm{s}}$ is commonly observed in droughtstressed plants (Cai et al., 2012; Jones and Tardieu, 1998; Nemali and van Iersel, 2008; Niu et al., 2006; Zollinger et al., 2006). Lower

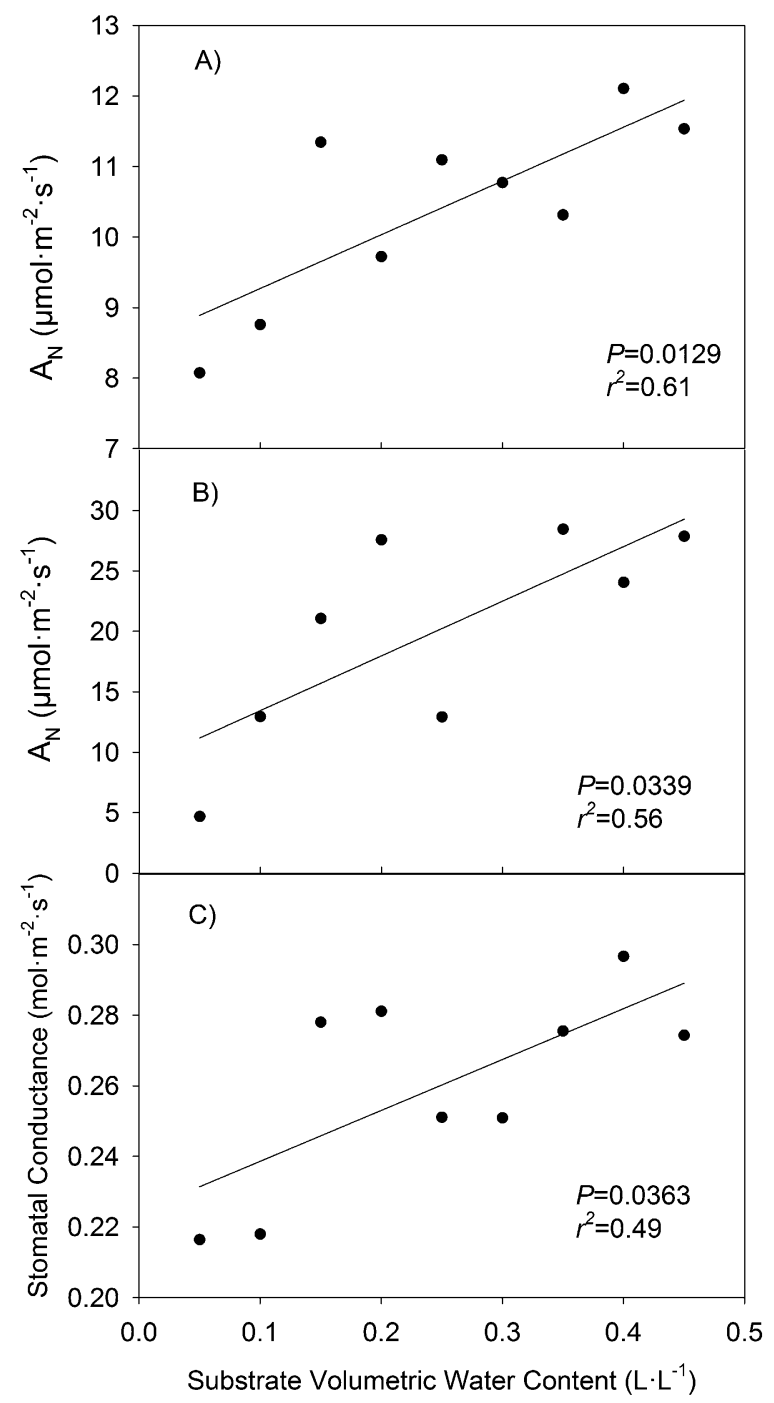

Fig. 5. Net photosynthetic rate $\left(\mathrm{A}_{\mathrm{N}}\right)$ of Canadian columbine $(\mathbf{A})$ and cheddar pink $(\mathbf{B})$ and stomatal conductance $\left(g_{\mathrm{s}}\right)$ of Canadian columbine $(\mathbf{C})$ grown at nine substrate volumetric water content $(\theta)$ set points. Data were measured on the upper-most fully expanded leaves. $P \leq 0.05$ was considered statistically significant. 
photosynthetic activity likely contributed to the reduced shoot biomass and leaf area observed at lower $\theta$ (Figs. 2 and 3).

If drought limits the ability of photosynthesis to use captured light energy by restricting $\mathrm{CO}_{2}$ supply and non-photosynthetic dissipation pathways are insufficient to quench the excess light energy, plant photosystems can suffer damage. This damage can be detected by differences in chlorophyll fluorescence between healthy and stressed plants, particularly the difference in $\mathrm{F}_{\mathrm{v}} / \mathrm{F}_{\mathrm{m}}$ (Maxwell and Johnson, 2000). In this study, $\theta$ treatments did not affect $\mathrm{F}_{\mathrm{v}} / \mathrm{F}_{\mathrm{m}}$ for Canadian columbine, indicating that PSII was not damaged. In cheddar pink, there was a modest reduction in $F_{v} / F_{m}$ that ranged from 0.803 to 0.84 at $\theta$ of 0.10 and $0.45 \mathrm{~L} \cdot \mathrm{L}^{-1}$, respectively. The lowest $\mathrm{F}_{\mathrm{v}} / \mathrm{F}_{\mathrm{m}}(0.786)$ was measured at the lowest $\theta$ $\left(0.05 \mathrm{~L} \cdot \mathrm{L}^{-1}\right)$. These results suggest that Canadian columbine may possess a slightly greater capacity to counter photodamage through alternative mechanisms when photochemistry is stomatal-limited such as increased photorespiration (Voss et al., 2013).

For cheddar pink, although $\mathrm{F}_{\mathrm{v}} / \mathrm{F}_{\mathrm{m}}$ may indicate drought stress in some cases, it is not as sensitive as other physiological and morphological indicators (Maxwell and Johnson, 2000). Small differences in $F_{v} / F_{m}$ (in this case 4\%) may be hard to correlate with lower photosynthetic rates when water stress is not severe (Karukstis, 1991). In this experiment, plants were gradually exposed to low rates of drought stress that reduced photosynthesis and $g_{\mathrm{S}}$ but had only a modest impact on $\mathrm{F}_{\mathrm{v}} / \mathrm{F}_{\mathrm{m}}$ for cheddar pink and no detectable differences for Canadian columbine. Previous researchers have reported small or no differences in $\mathrm{F}_{\mathrm{v}} / \mathrm{F}_{\mathrm{m}}$ when plants were droughtstressed. Starman and Lombardini (2006) reported that drought did not affect $\mathrm{F}_{\mathrm{v}} / \mathrm{F}_{\mathrm{m}}$ when mealycup sage and fan flower were exposed to two subsequent 10 -d drought cycles $(\theta$ of the upper $6 \mathrm{~cm}$ of substrate reached $\left.0.13 \mathrm{~L} \cdot \mathrm{L}^{-1}\right)$, whereas $\mathrm{F}_{\mathrm{v}} / \mathrm{F}_{\mathrm{m}}$ of lantana was reduced by $2.4 \%$ compared with the control on Day 8 of the first drought cycle. Niu et al. (2008) exposed two cultivars and two breeding lines of oleander (Nerium oleander) to 12-week cyclic drought stress, and decreases in $\mathrm{F}_{\mathrm{v}} / \mathrm{F}_{\mathrm{m}}$ of drought-stressed plants were observed in only two of the four clones. Sánchez-Blanco et al. (2009) observed no drought-induced damage to PSII of zonal geranium.

\section{Conclusion}

Substrate volumetric water content $(\theta)$ affected growth and morphology of rosemary, Canadian columbine, and cheddar pink. Shoot fresh weight of rosemary increased as plants were grown at a higher $\theta$. If crops are to be harvested fresh, we recommend growing rosemary at $\theta$ greater than $0.20 \mathrm{~L} \cdot \mathrm{L}^{-1}$ up to a maximum $\theta$ of $0.4 \mathrm{~L} \cdot \mathrm{L}^{-1}$ to obtain high yield (i.e., fresh weight). Substrate $\theta$ did not affect biomass production of Canadian columbine. However, Canadian columbine height was reduced when plants were grown in drier substrates. Therefore, it is possible to use drought as a substitute for chemical growth retardants in production of Canadian columbine. Cheddar pink had the highest biomass production at $\theta$ of $0.35 \mathrm{~L} \cdot \mathrm{L}^{-1}$; increasing $\theta$ above this set point did not increase plant growth. Reductions in overall size of Canadian columbine and cheddar pink at lower $\theta$ were caused at least in part by reductions in leaflevel $\mathrm{A}_{\mathrm{N}}$.

Sensor-automated irrigation systems conserve water, and no leaching was observed during the experiment. Canadian columbine used less than $5.5 \mathrm{~L}$ of water even when grown at the highest $\theta\left(0.45 \mathrm{~L} \cdot \mathrm{L}^{-1}\right)$ for 10 weeks. Low quantities of water were used to grow all cheddar pink; even the largest plants were irrigated with no more than $15 \mathrm{~L}$ of water during the entire experiment. IWUE was not influenced by $\theta$ for both species. High-quality plants may be grown in a sensor-automated irrigation system using relatively low quantities of water.

\section{Literature Cited}

Armitage, A.M. 2008. Herbaceous perennial plants: A treatise on their identification, culture, and garden attributes. 3rd Ed. Stipes Publishing, L.L.C., Champaign, IL.

Beeson, R.C., Jr., M.A. Arnold, T.E. Bilderback, B. Bolusky, S. Chandler, H.M. Gramling, J.D Lea-Cox, J.R. Harris, P.J. Klinger, H.M. Mathers, J.M. Ruter, and T.H. Yeager. 2004. Strategic vision of container nursery irrigation in the next ten years. J. Environ. Hort. 22:113-115.

Belayneh, B.E., J.D. Lea-Cox, and E. Lichtenberg. 2013. Costs and benefits of implementing sensorcontrolled irrigation in a commercial pot-in-pot container nursery. HortTechnology 23:760-769.

Bilderback, T.E. 2002. Water management is key in reducing nutrient runoff from container nurseries. HortTechnology 12:541-544.

Boyer, J.S. 1970. Leaf enlargement and metabolic rates in corn, soybean, and sunflower at various leaf water potentials. Plant Physiol. 46:233-235.

Burnett, S.E. and M.W. van Iersel. 2008. Morphology and irrigation efficiency of Gaura lindheimeri grown with capacitance sensor-controlled irrigation. HortScience 43:1555-1560.

Cai, X.Y., T. Starman, G.H. Niu, C. Hall, and L. Lombardini. 2012. Response of selected garden roses to drought stress. HortScience 47:10501055.

Chappell, M., S.K. Dove, M.W. van Iersel, P.A. Thomas, and J. Ruter. 2013. Implementation of wireless sensor networks for irrigation control in three container nurseries. HortTechnology 23:747-753

Eakes, D.J., R.D. Wright, and J.R. Seiler. 1991. Moisture stress conditioning effects on Salvia splendens 'Bonfire'. J. Amer. Soc. Hort. Sci. 116:716-719.

Garland, K.F., S.E. Burnett, M.E. Day, and M.W. van Iersel. 2012. Influence of substrate water content and daily light integral on photosynthesis, water use efficiency, and morphology of Heuchera americana. J. Amer. Soc. Hort. Sci. 137:57-67.

Jones, H.G. 2007. Monitoring plant and soil water status: Established and novel methods revisited and their relevance to studies of drought tolerance. J. Expt. Bot. 58:119-130.

Jones, H.G. and F. Tardieu. 1998. Modeling water relations of horticultural crops: A review. Sci. Hort. 74:21-46.
Karukstis, K.K. 1991. Chlorophyll fluorescence as a physiological probe of the photosynthetic apparatus, p. 769-795. In: Scheer, H. (ed.). Chlorophylls. CRC Press, Baca Raton, FL.

Khalil, S.K., R. St. Hilaire, M. O'Connell, and J. Mexal. 2008. Growth of moonshine yarrow on a limited moisture budget. J. Environ. Hort. 26:70-74.

Kim, J. and M.W. van Iersel. 2009. Daily water use of abutilon and lantana at various substrate water contents. Proc. SNA Res. Conf. 54:1216.

Kramer, P.J. and J.S. Boyer. 1995. Water relations of plants and soils. Academic Press, San Diego, NY.

Latimer, J.G. and R.D. Oetting. 1999. Conditioning treatments affect insect and mite populations on bedding plants in the greenhouse. HortScience 34:235-238

Lea-Cox, J.D. and D.S. Ross. 2001. A review of the federal clean water act and the Maryland water quality improvement act: The rationale for developing a water and nutrient management planning process for container nursery and greenhouse operations. J. Environ. Hort. 19: 226-229.

Lichtenberg, E., J. Majsztrik, and M. Saavoss. 2013. Profitability of sensor-based irrigation in greenhouse and nursery crops. HortTechnology 23:770-774.

Maxwell, K. and G.N. Johnson. 2000. Chlorophyll fluorescence-A practical guide. J. Expt. Bot. 51:659-668.

Million, J., T. Yeager, and J. Albano. 2007. Consequences of excessive overhead irrigation on runoff during container production of sweet viburnum. J. Environ. Hort. 25:117125 .

Naasz, R., J.C. Michel, and S. Charpentier. 2005 Measuring hysteretic hydraulic properties of peat and pine bark using a transient method. Soil Sci. Soc. Amer. J. 69:13-22.

Nelson, P.V. 2012. Greenhouse operation and management. 7th Ed. Prentice Hall, Upper Saddle River, NJ.

Nemali, K.S. and M.W. van Iersel. 2006. An automated system for controlling drought stress and irrigation in potted plants. Sci. Hort. 110: 292-297.

Nemali, K.S. and M.W. van Iersel. 2008. Physiological responses to different substrate water contents: Screening for high water-use efficiency in bedding plants. J. Amer. Soc. Hort. Sci. 133:333-340.

Niu, G.H., D.S. Rodriguez, and W. Mackay. 2008. Growth and physiological responses to drought stress in four oleander clones. J. Amer. Soc. Hort. Sci. 133:188-196.

Niu, G.H., D.S. Rodriguez, and Y.-T. Wang. 2006. Impact of drought and temperature on growth and leaf gas exchange of six bedding plant species under greenhouse conditions. HortScience 41:1408-1411.

Sánchez-Blanco, M.J., S. Álvarez, A. Navarro, and S. Bañón. 2009. Changes in leaf water relations, gas exchange, growth and flowering quality in potted geranium plants irrigated with different water regimes. J. Plant Physiol. 166: 467-476.

Starman, T. and L. Lombardini. 2006. Growth, gas exchange, and chlorophyll fluorescence of four ornamental herbaceous perennials during water deficit conditions. J. Amer. Soc. Hort. Sci. 131: 469-475.

Taiz, L. and E. Zeiger. 2010. Plant physiology. 5th Ed. Sinauer, Sunderland, MA.

Tyler, H.H., S.L. Warren, and T.E. Bilderback. 1996. Cyclic irrigation increases irrigation 
application efficiency and decreases ammonium losses. J. Environ. Hort. 14:194-198.

U.S. Department of Agriculture. 2013. The PLANTS database. 25 Apr. 2013. <http://www.plants. usda.gov/>.

van Iersel, M.W., M.R. Chappell, and J. Lea-Cox. 2013. Sensors for improved efficiency of irrigation in greenhouse and nursery production. HortTechnology 23:735-746. van Iersel, M.W., S. Dove, J. Kang, and S.E. Burnett. 2010. Growth and water use of petunia as affected by substrate water content and daily light integral. HortScience 45:277282.

Voss, I., B. Sunil, R. Scheibe, and A.S. Raghavendra. 2013. Emerging concept for the role of photorespiration as an important part of abiotic stress response. Plant Biol. 15:713-722.
Williams, M.H., E. Rosenqvist, and M. Buchhave. 1999. Response of potted miniature roses (Rosa $\times$ hybrida) to reduced water availability during production. J. Hort. Sci. Biotechnol. 74:301308.

Zollinger, N., R. Kjelgren, T. Cerny-Koenig, K. Kopp, and R. Koenig. 2006. Drought responses of six ornamental herbaceous perennials. Sci. Hort. 109:267-274. 